\title{
ESTRATÉGIAS DE LEITURA NO ENSINO DE LÍNGUA INGLESA: UMA COMPARAÇÃO ENTRE O LIVRO DIDÁTICO E A BASE NACIONAL COMUM CURRICULAR (BNCC)
}

\author{
ESTRATEGIAS DE LECTURA EN LA ENSEÑANZA DEL LENGUAJE INGLÉS: UNA \\ COMPARACIÓN ENTRE EL LIBRO DIDÁCTICO Y LA BASE CURRICULAR \\ NACIONAL COMÚN (BNCC)
}
READING STRATEGIES IN ENGLISH LANGUAGE TEACHING: A COMPARISON BETWEEN THE EDUCATIONAL BOOK AND THE NATIONAL COMMON CURRICULAR BASE (BNCC)

\author{
Juliana Ferreira dos SANTOS ${ }^{1}$
}

RESUMO: O tema deste artigo são as atividades de leitura no ensino de língua inglesa. $O$ objetivo é verificar as propostas de leitura da seção "Reading" no do livro didático "Beyond Words" do $6^{\circ}$ ano do Ensino Fundamental II. O objetivo específico é analisar as prescrições para o eixo leitura na Base Nacional Comum Curricular do $6^{\circ}$ ano e verificar as atividades de compreensão leitora do livro didático. Metodologicamente, trata-se de uma pesquisa documental, de cunho qualitativo e interpretativo. Teoricamente, este artigo se baseia na concepção sociocognitiva de leitura e nos estudos de leitura em língua inglesa Além de tomar como parâmetro algumas prescrições da BNCC (BRASIL, 2018). Os resultados sinalizam que as estratégias de leitura propostas neste documento são muito reduzidas em relação ao livro didático analisado. Conclui-se que o livro didático analisado está atualizado com relação à BNCC e incorpora muitos pressupostos teóricos de estudos linguísticos contemporâneos.

PALAVRAS-CHAVE: Ensino de língua inglesa. Leitura. Livro didático. BNCC.

RESUMEN: El tema de este artículo son las actividades de lectura en la enseñanza del idioma inglés. El objetivo general es verificar las propuestas de lectura en la sección "Reading" del libro de texto "Beyond Words" para el $6^{\circ}$ año de la Escuela Primaria II. El objetivo específico es analizar las prescripciones para el eje de lectura en el VI Base Común Curricular Nacional y verificar las actividades de comprensión lectora del libro de texto. Metodológicamente, se trata de una investigación documental, de carácter cualitativo e interpretativo. Teóricamente, este artículo se basa en la concepción sociocognitiva de la lectura, en los estudios de lectura en lengua inglesa, Además de tomar como parámetro algunas prescripciones de BNCC (BRASIL, 2018). Los resultados indican que las estrategias de lectura propuestas en este documento son muy reducidas en relación al libro de texto analizado. Se concluye que el libro de texto analizado está actualizado en relación al BNCC e incorpora muchos supuestos teóricos de los estudios lingüísticos contemporáneos.

PALABRAS CLAVE: Enseñanza del Idioma Inglés. Leyendo. Libro de texto. BNCC.

${ }^{1}$ Secretaria Municipal de Educação (SME), Taubaté - SP - Brasil. Professora Estatutária de Língua Inglesa. Mestrado em Linguística Aplicada (UNITAU). ORCID: https://orcid.org/0000-0001-6179-1967. E-mail: jubeauty@bol.com.br 
ABSTRACT: The topic of this article is reading activities in English language teaching. The general objective is to analyze the reading activities proposed in the reading section of the 6th year textbook, "Beyond Words". Specifically, the objective is to analyze the reading strategies proposed by the National Common Curricular Base for the 6th year and the strategies proposed in the textbook. Methodologically, it is documentary research, of a qualitative and interpretative nature. Theoretically, this article is based on the sociocognitive conception of reading, on studies of reading in the English language, besides that, it uses, as a parameter, some BNCC prescriptions (BRASIL, 2017). The results indicate that the reading strategies proposed in this document are reduced when compared to the proposed in the textbook. It is concluded that the textbook is more updated than the BNCC and it incorporates more theoretical assumptions of contemporary linguistic studies.

KEYWORDS: English language teaching. Reading. Textbook. BNCC.

\section{Introdução}

Este artigo apresenta um recorte da dissertação apresentada no programa de pós graduação em Linguística Aplicada da Universidade de Taubaté sobre "Atividades de leitura no ensino de língua inglesa: uma análise no livro didático Beyond Words do $6^{\circ}$ ano do Ensino Fundamental II". Neste trabalho, focaliza-se as atividades de leitura no ensino de língua inglesa, mais especificamente as atividades propostas na seção Reading do livro didático Beyond Words do $6^{\circ}$ ano do Ensino Fundamental II.

O problema que motivou essa pesquisa é a necessidade de os professores saberem reconhecer as possíveis dificuldades nas atividades de leitura em um livro didático para que possam supri-las no preparo de suas aulas, como sinalizam outras pesquisas sobre o ensino de leitura

Sendo assim, estabeleceu-se como objetivo analisar as atividades de leitura propostas na seção Reading do livro didático "Beyond Words" do $6^{\circ}$ ano do Ensino Fundamental II.

A pesquisa vai contribuir para minimizar o problema que motivou a pesquisa. Dessa forma, os professores que vierem a ter contato com este artigo poderão tonar as atividades propostas no livro didático mais adequadas ao desenvolvimento de habilidades de leitura.

Teoricamente, este artigo se baseia na concepção sociocognitiva de leitura e nos estudos de leitura em língua inglesa. Além de tomar como parâmetro algumas prescrições da Base Nacional Comum Curricular - BNCC (BRASIL, 2018).

Este artigo é uma pesquisa documental, de cunho qualitativo e interpretativo. Foram realizados os seguintes procedimentos metodológicos: 1) seleção das atividades de leitura da seção Reading da Unidade 1 do livro didático "Beyond Words" do $6^{\circ}$ ano; $2^{\circ}$ análise das 
atividades de modo qualitativo e interpretativo; $3^{\circ}$ seleção das habilidades de leitura propostas na Base Nacional Comum Curricular de Língua Inglesa para o $6^{\circ}$ ano (BRASIL, 2018).

Nas próximas seções, este artigo apresenta a fundamentação teórica, os procedimentos metodológicos, os resultados, as considerações finais e as referências.

\section{Fundamentação teórica}

\section{A concepção sociocognitiva de leitura}

Até a segunda metade da década de 70, a leitura era considerada um processo de decodificação, ou seja, a leitura era entendida apenas como a capacidade de decifrar o código escrito para entender o seu significado (KLEIMAN, 2004). Segundo Solé (1996), a leitura era considerada um processo ascendente (Bottom up), no qual a decodificação era essencial para decifrar as letras, as palavras e as frases. O processo de leitura acontecia de forma passiva entre o leitor e o texto, o qual ocorria de baixo para cima e sempre do texto para o leitor.

Para Solé (1996), esse processo não era suficiente porque não considerava o conhecimento prévio, a formulação de hipóteses e nem os objetivos que o leitor tinha sobre um determinado texto. A decodificação é importante, contudo, não é a única habilidade para se levar a compreensão.

Para Marcuschi (2008), considerar a compreensão como sinônimo de decodificação está relacionado à concepção de língua estática, homogênea e não a concepção de língua heterogênea e como prática social. A decodificação não é suficiente, porque não se consegue compreender um texto e nem formar um cidadão mais crítico apenas decifrando-o. Para esse autor, considerar a compreensão como decifração é não reconhecer um texto como um "processo criativo, ativo e construtivo que vai além da informação estritamente textual" (MARCUSCHI, 2008, p. 61).

Por muitos anos, essa foi a visão de leitura que existiu em nossa sociedade porque a língua era vista como um sistema abstrato, homogêneo e não considerada sob os aspectos sociais e históricos. Essa concepção de língua surgiu da corrente estruturalista, a qual Ferdinand Saussure fazia parte. Para Marcuschi (2008, p. 59), essa perspectiva só se ocupava dos níveis estruturais (fonológico, morfológico, sintático e semântico), sem se ocupar do uso da língua, trabalhando as unidades de forma isolada e longe de qualquer contexto.

A partir dos anos 80, verificou-se que a língua envolve uma atividade cognitiva. Sendo assim, segundo Koch (2005), despertou-se a consciência de que para realizar qualquer ação era necessário um conjunto de operações cognitivas. Logo, percebeu-se que a leitura é uma 
atividade que abrange alguns processos psicológicos e não apenas a decodificação. Então, o enfoque mudou: passaram a considerar a leitura, segundo Solé (1996), como um processo interativo - ascendente (Bottom up) e descendente (Top down) ao mesmo tempo, no qual o leitor não apenas decifra (decodifica) as palavras, mas também faz uso de seus conhecimentos prévios e de recursos cognitivos.

Os avanços dos estudos no processo cognitivo da leitura trouxeram a percepção da importância da interação que ocorre entre o texto e o leitor durante a leitura. Dessa forma, a concepção de leitura como um processo interativo se mostrou mais adequada. Essa nova concepção "supõe que o leitor seja um processador ativo do texto, e que a leitura seja um processo constante de emissão e verificação de hipóteses que levam à construção da compreensão do texto e do controle da compreensão" (SOLÉ, 1996, p. 24). Ainda nas palavras dessa mesma autora, para ler é preciso não só saber decodificar um texto, mas também conhecer as estratégias que podem levar a compreender um texto, tais como: inferência, conhecimento prévio e objetivo de leitura.

A partir do final do século XX, com os avanços nos estudos em Linguística Aplicada, neurobiologia, antropologia e diversas áreas das ciências, houve uma grande reviravolta nos estudos cognitivos, pois constataram, conforme Kock (2005), que muitos dos nossos processos cognitivos são mediados pela linguagem, mas ocorrem na sociedade e não apenas nos indivíduos. Com isso, desenvolveu-se uma concepção sociocognitiva de leitura e ampliaram-se os conceitos de língua, conhecimento prévio e sua aquisição, texto e leitor.

Para Marcuschi (2008, p. 240), percebeu-se que:

[...] a língua é muito mais do que um sistema de estruturas fonológicas, sintáticas e lexicais. A língua não é sequer uma estrutura; ela é estruturada simultaneamente em vários planos, tais como o fonológico, o sintático, o semântico e o cognitivo, que se organizam no processo de enunciação. A língua é um fenômeno cultural, histórico, social e cognitivo que varia ao longo do tempo e de acordo com os falantes: ela se manifessa no seu funcionamento e é sensível ao contexto. Não é um sistema monolítico e transparente, para "fotografar" a realidade, mas é heterogênea e sempre funciona situadamente na relação dialógica, como ensina Bakhtin (1979).

Essa nova conceito de língua mostrou que para a aquisição do conhecimento prévio é preciso considerar o contexto histórico-social em que o leitor está inserido. Dessa maneira, além dos conhecimentos linguísticos, textuais e enciclopédicos, é necessário, segundo esse mesmo autor, aceitar conhecimentos sociais, antropológicos, históricos, factuais, científicos e muitos outros. 
A nova concepção de língua, como cita Marcuschi (2008), é usada para expressar os sentimentos e, por meio de cada enunciação, construímos um tipo diferente de texto, não frases soltas e desconexas, como se pensaram os estruturalistas. Atrelada a essa mudança de concepção está a nova concepção de texto.

O texto é muito mais que um conjunto de frases ou um produto acabado, identificaram que o texto está aberto a vários tipos de compreensões. Com isso vemos que o texto não é algo pronto, uma vez que está sempre em construção ao longo do tempo e das compreensões dos leitores (MARCUSCHI, 2008, p. 240).

O leitor construirá a compreensão a partir de uma relação entre texto-leitor e autor. Por isso, pode-se afirmar que a compreensão é "fruto do trabalho conjunto entre produtores e receptores em situações reais de uso de língua" (MARCUSCHI, 2008, p. 240). Portanto, o sentido não está no autor, nem no leitor e tão pouco no texto, mas sim na relação que há entre eles e nas suas atividades.

A concepção sociocognitiva de leitura considera os fatores cognitivos que ocorrem dentro dos leitores e os que ocorrem fora na sociedade. De acordo com Marcuschi, deve-se considerar também a visão de língua "heterogênea, social, histórica, cognitiva, indeterminada, variável, interativa e situada" (MARCUSCHI, 2008, p. 65). Dentro dessa nova perspectiva, o sentido é construído pelo texto, mas compreendido pelo leitor, visto que é uma atividade que ocorre dialogicamente entre ambos.

\section{Estratégias de leitura e o ensino de língua inglesa}

De acordo com Santorum e Scherer (2008), quando se fala em aquisição de leitura em segunda língua é salutar distinguir os termos habilidade e estratégia de leitura, uma vez que são usados de forma desregrada. Habilidade refere-se ao procedimento que é utilizada de forma inconsciente e estratégia refere-se ao procedimento que é usado de forma consciente, com um objetivo definido e que tem um domínio por parte do leitor. Para essas autoras, a distinção entre habilidade e estratégia é importante para os professores, pois dá uma direção sobre o que os leitores fazem no processo de leitura e as razões pelas quais o fazem

Segundo Santorum e Scherer (2008), as estratégias podem ser divididas em metacognitivas e cognitivas. As estratégias cognitivas propiciam a leitura do significado das palavras no contexto ou mesmo fazer uma leitura por alto (skimming) para buscar o assunto principal do texto. Por outro lado, as estratégias metacognitivas são aquelas que envolvem 
uma reflexão do indivíduo sobre seus processos, é o "saber sobre o próprio saber" (SANTORUM; SCHERES, 2008, p. 3).

Para Santorum e Scheres (2008), as práticas escolares devem desenvolver nos alunos o ensino explícito de estratégias para que possam se tornarem leitores proficientes, uma vez que na compreensão de leitura em língua estrangeira não basta apenas a decifração das palavras, uma vez que a decifração não envolve a competência comunicativa. Nessa perspectiva, o ensino de estratégia permite ao leitor se conscientizar sobre os processos que envolvem a compreensão e quando isso ocorre, ele passa a ser visto como um leitor ativo dentro do processo de compreensão, relacionando o sentido do texto aos seus conhecimentos prévios e identificando o uso real da língua. Dessa forma, como citam Santorum e Scheres (2008), os professores devem agir como "scaffolding" (andaimes) no processo inicial de aprendizagem da capacidade leitora, mediando o texto e o leitor.

Santorum e Scherer (2008) propõem o uso de três estágios para desenvolver as estratégias de leitura a fim de que elas se tornem automáticas, ou seja, metacognitivas. Utilizam-se dos seguintes termos: atividades de pré-leitura; atividade durante a leitura; e as atividades de pós-leitura. A atividade de pré-leitura é quando os leitores, por meio da previsão, decidem se vão ler ou não o texto. Os leitores são estimulados a partir do título, da edição e da data de publicação a fazerem uma leitura rápida. Nesse estágio, há também a predição. "Nela o aluno aprende a antecipar o conteúdo, a formular hipótese sobre as macro proposições que o texto deve conter e a pensar sobre o assunto do texto" (SANTORUM; SCHERES, 2008, p. 9).

Para as atividades durante a leitura, as autoras sugerem o estímulo dos leitores pelo uso de estratégia do autoquestionamento e o automonitoramento. $\mathrm{O}$ autoquestionamento pode ser feito pelo uso de inferências, monitoramento do que entendeu e da estrutura do texto. Já o auto monitoramento pode ocorrer pelo "monitoramento da própria compreensão, verificando se a compreensão está acontecendo efetivamente e adota estratégias de reparo caso não seja" (SANTORUM; SCHERES, 2008, p. 9).

No último estágio proposto pelas autoras, as atividades de pós-leitura é quando o leitor “é estimulado a relacionar o conteúdo lido com seu esquema já existente e a avaliá-lo à luz de suas próprias experiências e conhecimentos, promovendo uma maior integração com o texto" (SANTORUM; SCHERES, 2008, p. 10). Para essas autoras, durante a aplicação dos três estágios, é necessário despertar a consciência do leitor sobre o processo de leitura, além de mostrar a importância dos estágios para a compreensão leitora. 
Tomich (2009) também defende que a aula de leitura deve ser dividida em três momentos: pré-leitura, leitura e pós-leitura. Essa divisão tem fundamento porque cada fase tem um objetivo específico, o que contribui para a compreensão leitora dos estudantes. A fase de pré-leitura é aquela que é feita antes do aluno ler propriamente o texto e o objetivo é de verificar o que os alunos já sabem sobre o assunto do texto, motivá-los para a leitura do texto que virá em seguida e ajudá-los na construção do sentido do texto. Essa fase é um preparo para a próxima e pode ser formada por atividades como: discussão prévia do assunto, exploração de imagens, apresentação de um trecho de uma música ou de um filme que possa estabelecer relação com o assunto que será apresentado no texto, entre outras.

Para Tomitch (2009), a etapa da leitura é o momento em que o estudante receberá o texto e começará a leitura. Para isso, precisa ser bem preparada e com atividades que tenham objetivos específicos para os alunos. Dessa maneira, a leitura não será de decodificação nem de tentativa de traduzir o texto literalmente. Nessa fase, exercícios de verdadeiro ou falso, múltiplas escolhas e de respostas curtas ( $\operatorname{sim} /$ não) são importantes. Contudo, há outras atividades que podem tornar a aula de leitura mais dinâmica e atraente, tais como "completar ou construir diagramas ou tabelas, relacionar figuras com o texto lido, reorganizar parágrafos para formar um texto, entre outras" (TOMITCH, 2009, p. 196).

A fase de pós-leitura é aquela que vai levar o aluno a estabelecer uma relação entre o que leu no texto e sua realidade. O objetivo dessa fase é solidificar o que foi aprendido, fazendo com que o estudante possa utilizar o que leu em situações reais, como exemplo, novas discussões, pesquisas, entre outros.

Na seleção de estratégias de leitura a autora sugere o uso de palavras cognatas, o uso de leitura rápida para buscar a ideia geral do texto (skimming) e o uso da leitura para buscar a informação específica (scanning) e, por serem mais básicas, podem ser ensinadas em níveis iniciais. Já as atividades como resumos e resenhas, por exigirem maior esforço cognitivo, devem ser ensinadas nos níveis avançados.

Donini, Platero e Weigel (2013) também relatam que as estratégias de leitura podem ser divididas em atividades de pré-leitura, leitura e pós-leitura. $\mathrm{Na}$ fase de pré-leitura, as autoras sugerem o uso da antecipação. Com essa estratégia os conhecimentos prévios serão acionados, o que levará a uma expectativa em relação ao tema, ao tipo de texto, a língua e sobre o suporte textual. Na fase de leitura, as autoras citam as três categorias que são as mais utilizadas: o skimming permite uma leitura rápida para aprender o assunto geral; o scanning permite uma leitura em busca de informações mais específicas, e; o, detailed reading possibilita ler várias vezes ou escutar várias vezes para fazer um estudo detalhado. 
$\mathrm{Na}$ fase de pós-leitura, as autoras abordam o uso de atividades que levem a ativação do pensamento crítico. Nessa fase, elas sugerem o trabalho com estratégias de elaboração pessoal e que levem o aluno a

[...] elaborar interpretações baseadas em informações nem sempre explícitas no texto; posicionar-se criticamente em relação ao tema e rever suas opiniões; tratar a informação do texto de forma adequada para transpô-lo para outros tipos de textos (DONNINI; PLATERO; WEIGEL, 2013, p. 63).

De modo geral, as propostas para o ensino de leitura na Língua Inglesa sugeridas pelas autoras Santorum e Scherer (2008), Tomich (2009), e Donnini, Platero e Weigel (2013) são semelhantes. Todas as autoras abordam o uso de estratégias de leitura e a divisão das atividades de leitura em três momentos como sendo uma estratégia eficaz. Basicamente, todas as autoras defendem a necessidade de se ativar o conhecimento prévio, estabelecer objetivos e fazer inferências. Abordam também a importância de se relacionar informações do texto ao conhecimento já adquirido; a importância do uso de palavras cognatas e a necessidade de se buscar a ideia geral (skimming) e a ideia específica (scanning) no texto.

\section{A Base Nacional Comum Curricular (BNCC) e o ensino de leitura de língua inglesa no $6^{\circ}$ ano do ensino fndamental II}

De acordo com a BNCC, a leitura é vista como uma prática de linguagem que surge a partir da interação do leitor com o texto, por meio da interpretação e compreensão dos gêneros em língua inglesa que circulam na sociedade. Sendo assim, pode favorecer o desenvolvimento de estratégias para identificação textual e de reflexão crítica a partir dos temas tratados nos textos (BRASIL, 2018).

Assim, o ensino de leitura por meio da diversidade de gêneros textuais podem favorecer diferentes modos de leitura ( para ter uma ideia geral sobre o assunto, leitura para buscar informações mais específicas ou para se compreender detalhadamente) e objetivos diversos. O contato do aluno com gêneros escritos e multimodais diversificados, que sejam relevantes não só para a vida escolar, mas para além dela (incluindo a vida social e a cultural) e a compreensão que se faz sobre os temas, podem ser essenciais para desenvolver uma leitura crítica, bem como a possibilidade de se aprender a língua inglesa de forma criativa e autônoma (BRASIL, 2018).

As atividades de leitura, segundo a BNCC, apoiadas em práticas de leituras já internalizadas em sua língua materna, devem ser realizadas de forma contextualizadas e significativas para os alunos e devem ser organizadas em: pré-leitura, leitura e pós-leitura 
(BRASIL, 2018). Este documento defende que as práticas de leitura devem ser articuladas ao conhecimento prévio dos alunos e prescreve algumas habilidades de leitura, como aparece no quadro 1 abaixo.

\section{Quadro 1 - Proposta da BNCC para o eixo leitura em Língua Inglesa no $6^{\circ}$ ano}

EIXO LEITURA- Práticas de leitura de textos diversos em língua inglesa (verbais, verbo-visuais, multimodais) presentes em diferentes suportes e esferas de circulação. Tais práticas envolvem articulação com os conhecimentos prévios dos alunos em língua materna e/ou outras línguas.

\begin{tabular}{|c|c|c|}
\hline \multirow[t]{2}{*}{ Estratégias de leitura } & $\begin{array}{l}\text { Hipóteses sobre a finalidade de um } \\
\text { texto }\end{array}$ & $\begin{array}{l}\text { (EF06LI07). Formular hipóteses sobre a } \\
\text { finalidade de um texto. }\end{array}$ \\
\hline & $\begin{array}{l}\text { Compreensão geral e específica: } \\
\text { leitura rápida (skimming, scanning) }\end{array}$ & $\begin{array}{l}\text { (EF06LI08). Identificar o assunto de } \\
\text { um texto, reconhecendo sua } \\
\text { organização textual e palavras cognatas. } \\
\text { (EF06LI09). Localizar informações } \\
\text { específicas em texto. }\end{array}$ \\
\hline $\begin{array}{l}\text { Práticas de } \begin{array}{l}\text { leitura } \\
\text { construção } \\
\text { lexical. }\end{array} \\
\text { de }\end{array}$ & $\begin{array}{l}\text { Construção de repertório lexical e } \\
\text { autonomia leitora }\end{array}$ & $\begin{array}{l}\text { (EF06LI10). Conhecer a organização de } \\
\text { um dicionário bilíngue (impresso e/ou } \\
\text { on-line) para construir repertório } \\
\text { lexical. } \\
\text { (EF06LI11). Explorar ambientes } \\
\text { virtuais e/ou aplicativos para construir } \\
\text { repertório lexical na língua inglesa. }\end{array}$ \\
\hline $\begin{array}{l}\text { Atitudes e disposições } \\
\text { favoráveis do leitor }\end{array}$ & $\begin{array}{l}\text { Partilha de leitura com mediação do } \\
\text { professor }\end{array}$ & $\begin{array}{l}\text { (EF06LI12). Interessar-se pelo texto } \\
\text { lido, compartilhando suas ideias sobre o } \\
\text { que o texto informa/comunica. }\end{array}$ \\
\hline
\end{tabular}

Fonte: Brasil (2018, p. 248-249)

No quadro sobre a proposta da BNCC para o eixo leitura em Língua Inglesa no $6^{\circ}$ ano, fica explícita a importância de se usar estratégias no ensino de leitura em Língua Inglesa, como: formular hipóteses sobre a finalidade de um texto; reconhecer o assunto, reconhecer a organização de um texto e identificar palavras cognatas; localizar informações específicas em um texto.

\section{Procedimentos metodológicos}

Foram selecionadas como o corpus da pesquisa as atividades de leitura da unidade 1 da seção Reading do livro didático "Beyond Words" do $6^{\circ}$ ano. Este material foi aprovado 
pelo Programa Nacional do Livro Didático (PNLD) de 2020. Essa coleção apresenta oito unidades temáticas e dois projetos. As unidades estão divididas em seções: Time to Think; Reading; Listening and speaking/Listening and writing/Reading and writing ; Style of the genre ; Pit stop ; Think it over e Integrate.

Para a análise, foram considerados os textos e as atividades da seção Reading, por ser a seção que tem o objetivo principal de estimular o desenvolvimento da compreensão leitora e, dessa forma, espera-se ser a seção em que apareçam o uso de estratégias de leitura.

Reading é a seção que apresenta as atividades de compreensão leitora e, para cada unidade, apresenta de duas a três Tasks e esta subdividida em Before Reading (subseção que corresponde à fase de pré-leitura, cujo propósito é acionar os conhecimentos prévios e estimular as hipóteses de leitura sobre o texto a ser lido), Read to learn more (corresponde à fase da leitura, que tem como foco apresentar o texto aos alunos sempre propondo que façam a leitura com alguns objetivos em mente) e Constructing meanings.

(é a subseção que corresponde à fase da compreensão leitora e do conhecimento do gênero discursivo a ser abordado ). Assim, foram selecionadas as atividades de leitura da unidade 1 da seção Reading do LD, a qual inclui três Tasks.

\section{Resultados}

Na Unidade 1, observa-se que na Task 1 e Task 2 há a estratégia de divisão da leitura em etapas, sendo elas: pré-leitura, leitura e compreensão detalhada. Na Task 3, além dessas etapas, observa-se a etapa pós-leitura, que estabelece uma relação com todos os textos lidos.

$\mathrm{Na}$ etapa de pré-leitura (Before Reading) da Task 1, no final da página 19 e no início da página 20 , observa-se a estratégia de ativar o conhecimento prévio sobre documentos pessoais. Na etapa de leitura (Read to learn more), na Task 1, página 20, observa-se que a estratégia de leitura utilizada foi a de estabelecer objetivo de leitura: identificar os tipos de documentos e verificar as informações presentes neles. $\mathrm{Na}$ etapa de Compreensão Leitora (Constructing meanings) na Task 1 (pág. 21), as estratégias utilizadas foram: identificar informações específicas, inferir o sentido de palavras no texto, compreender globalmente o texto, fazer inferências e formular hipóteses.

Na sequência, se inicia a Task 2. O texto que está na página 22 é uma certidão de nascimento. Na etapa de leitura (Reading), página 23, observa-se que a estratégia utilizada foi estabelecer objetivos de leitura: ler para verificar dados informados em certidões de nascimento e comparar esta certidão de nascimento com a brasileira, como aparece na figura 
da página anterior. $\mathrm{Na}$ etapa de Compreensão Leitora (Constructing meanings), na Task 2 (pág. 24), observa-se o uso das estratégias de leitura: identificar informações específicas no texto e refletir sobre as características composicionais do gênero certidão de nascimento.

Na sequência dessas atividades, a Task 3, vai abordar a temática de dados pessoais em outro gênero discursivo, a apresentação pessoal em um blog. Na etapa de pré-leitura da Task 3, página 24, a estratégia de leitura utilizada foi a ativação do conhecimento prévio sobre o gênero discursivo apresentação pessoal e formulação de hipóteses sobre o gênero, como se vê na questão 1 reproduzida na figura 11. A questão 2 provoca o levantamento de hipóteses sobre a fonte do texto e a temática.

O final da página 24 traz o início da seção Read to learn more, em que observa-se a estratégia de estabelecer objetivos de leitura para o texto da próxima página, que é uma apresentação pessoal em um blog. Na etapa de Compreensão Leitora (Constructing meanings) da Task 3 (pág. 25), as estratégias utilizadas foram: compreender globalmente o texto, fazer inferências e identificar informações específicas no texto. Como se pode observar na figura 12.

Na etapa pós-leitura (Think more about it), nas páginas 25 e 26, as estratégias utilizadas foram identificar e comparar as características composicionais dos gêneros em questão.

\section{Considerações finais}

No quadro sobre a proposta da BNCC para o eixo leitura em Língua Inglesa no $6^{\circ}$ ano, fica explícita a importância de se usar estratégias no ensino de leitura em Língua Inglesa, tais como: formular hipóteses sobre a finalidade de um texto; reconhecer o assunto, reconhecer a organização de um texto e identificar palavras cognatas; localizar informações específicas em um texto. Essas são algumas das estratégias de leitura propostas por autores que foram mencionados na fundamentação teórica desta pesquisa e na Unidade 1 do livro didático analisado, porém percebe-se que este documento apresenta um número muito reduzido de estratégias que poderiam estar presentes nas orientações já para o $6^{\circ}$ ano. Na descrição do Eixo Leitura, menciona-se "articular com os conhecimentos prévios dos alunos"(BRASIL, 2018, p. 244), porém não há uma proposta de estratégia de pré-leitura para que isso ocorra. Além disso, no quadro também não há a divisão da leitura em três momentos como uma estratégia a ser utilizada. 
Encontram-se no livro didático, nas atividades de leitura propostas na unidade $1 \mathrm{da}$ seção Reading, as estratégias: dividir a leitura em três momentos; ativar o conhecimento prévio sobre o assunto; estabelecer objetivos de leitura, relacionar a leitura prévia; usar palavras cognatas; usar a leitura para buscar a ideia geral (skimming); usar a leitura para buscar a informação específica (scanning), sintetizar e inferir. Nesse aspecto, portanto, apenas falta no livro didático uma fundamentação teórica sobre a importância do uso de estratégias de leitura para que os professores possam compreender melhor a intenção de cada atividade proposta nesta seção. Apesar disso, podemos concluir que os autores do livro didático analisado foram além das estratégias propostas pela BNCC (BRASIL, 2018).

\section{REFERÊNCIAS}

BAKHTIN, M. Estética da criação verbal. Introdução e tradução do russo Paulo Bezerra; Prefácio à edição francesa Tzvetan Todorov. 4. ed. São Paulo: Martins Fontes, 2003.

BRASIL. Ministério da Educação. Secretaria de Educação Básica. Base Nacional Comum Curricular (BNCC). Brasília, DF: MEC; SEB, 2018. Disponível em: $\mathrm{http}$ //basenacionalcomum.mec.gov.br/images/BNCC_EI_EF_110518_versaofinal_site.pdf. Acesso em: 30 abr. 2019.

DONNINI, L.; PLATERO, L.; WEIGEL, A. Ensino de língua inglesa. Coleção Ideias em Ação. São Paulo, SP: Cengage Learning, 2013.

KLEIMAN, A. Abordagens da leitura. SCRIPTA, Belo Horizonte, v. 7, n. 14, p. 13-22, 2004. Disponível em: http://periodicos.pucminas.br/index.php/scripta/article/view/12538. Acesso em 15 set. 2019.

KOCH, I. G. V. A construção dos sentidos no discurso: uma abordagem sociocognitiva. Investigações, Recife, v. 18, n. 2, p. 9-38, 2005. Disponível em: https://periodicos.ufpe.br/revistas/INV/article/view/1478. Acesso em: 10 dez. 2020.

MARCUSCHI, L. A. Produção textual, análise de gênero e compreensão. São Paulo, SP: Parábola, 2008. p. 237-241.

SANTORUM, K.; SCHERER, L. C. O papel do ensino de estratégias para o desenvolvimento da leitura em segunda língua (L2). ReVEL, v. 6, n. 11, agosto de 2008. Disponível em: http://www.revel.inf.br/files/artigos/revel_11_o_papel_do_ensino_de_estrategias.pdf. Acesso em: 10 set. 2019.

SOLÉ, I. Estratégias de leitura. 6. ed. Porto Alegre: Artmed, 1996.

TOMITCH, L. M. B. Aquisição de leitura em língua inglesa. In: LIMA, D. C. (Org.). Ensino e aprendizagem de língua inglesa: conversas com especialistas. São Paulo: Parábola Editorial, 2009. p. 191-201. 


\section{Como referenciar este artigo}

SANTOS, J. F. Estratégias de leitura no ensino de língua inglesa: uma comparação entre o livro didático e a base nacional comum curricular. Rev. EntreLínguas, Araraquara, v. 7, n. 00, p. e021004, 2021. e-ISSN: 2447-3529. DOI: https://doi.org/10.29051/el.v7i00.14218

Submetido em: 23/09/2020

Revisões requeridas: 03/11/2020

Aprovado em: $14 / 03 / 2021$

Publicado em: 01/06/2021 